\title{
SENTENCIA SOBRE TRÁFICO DE SEMILLAS DE CANNABIS SATIVA: UNA EXPRESIÓN DEL MODELO POLÍTICO-CRIMINAL DE REDUCCIÓN DE DAÑOS
}

\author{
Comentario de José Ángel Fernández Cruz
}

\author{
$4^{\circ}$ TRIBUNAL ORAL EN LO PENAL DE SANTIAGO ${ }^{1}$ \\ RUC: 0600200858-9 \\ RIT 11-2008
}

Santiago, cinco de marzo de dos mil ocho.

\section{VISTO, OÍDO Y CONSIDERANDO:}

PRIMERO: Tribunal e intervinientes. Que con fecha veinticinco, veintiséis, veintisiete, veintiocho y veintinueve de febrero de dos mil ocho, ante esta sala del Cuarto Tribunal Oral en lo Penal de Santiago, presidida por Don Antonio Ulloa Márquez e integrada por los jueces, don José Flores Ramírez y don Pedro Suárez Nieto se llevó a efecto la audiencia de juicio oral para conocer la acusación en contra de Angello Luis Bragazzi Padilla, cédula nacional de identidad $N^{\circ} 8.626 .525-7$, chileno, natural de Antofagasta, empresario, nacido el $1^{\circ}$ de noviembre de 1958, 49 años de edad, casado, domiciliado en Pasaje Santa Julia N ${ }^{\circ}$ 1150-J, comuna de La Florida, de esta ciudad de Santiago.

Fue parte acusadora del presente juicio el Ministerio Público, representado por los Fiscales adjuntos, don Jaime Retamal Herrera y doña Macarena Cañas Aranda y la defensa del acusado estuvo a cargo del Defensor Penal Privado don Pedro Mendoza Martínez.

Todos con domicilio y forma de notificación ya registrados en el Tribunal.

SEGUNDO: Acusación. Los hechos materia de la acusación, según se lee en el auto de apertura del juicio oral son los siguientes: "En virtud de una denuncia formulada por un Senador de la República, se pudo determinar que el acusado ANGELLO LUIS BRAGAZZI PADILLA, sin tener autorización de ninguna especie, indujo, promovió y facilitó el uso o consumo de sumidades floridas del género cannabis sativa (conocido vulgarmente como maribuana) mediante la oferta y distribución a terceros indeterminados, semillas de dicha especie vegetal, insumos, herramientas y conocimientos sobre las técnicas para su plantación, cultivo y cosecha bajo condiciones controladas y clandestinas para lograr su mejor rendimiento en términos de producción de las mayores concentraciones posibles de tetra-bidrocannabinol, principio activo alucinógeno de la especie cannabis.

${ }^{1}$ El presente comentario excluye, debido a la extensión del fallo, los Considerandos relativos a las alegaciones de las partes y a los medios de prueba. 
La oferta de las semillas, insumos, herramientas y Know-How la hacía el acusado a través de una página web que mantenía habilitada en Internet bajo el dominio www.closet.cl en la que publicitaba su número de teléfono celular para realizar los contactos y recibir las solicitudes de suministro provenientes de terceras personas. Asimismo, el acusado utilizó una entrevista publicada en un diario escrito el 31 de marzo de 2006, en la que ofreció e incitó en forma masiva a los miembros de la comunidad, a la adquisición y cultivo de las referidas semillas, advirtiendo incluso de los efectos físicos y psíquicos que produce el consumo de cannabis sattiva.

El pago del precio por los suministros ofertados por el acusado eran recibidos por éste personalmente o a través del depósito que hacían los terceros interesados en una cuenta de aborro bancaria de la que el acusado es su titular. Las entregas las hacía el acusado personalmente o a través de servicios de courrier.

En ese contexto, el 21 de abril de 2006, en el domicilio ubicado en calle Santa Elvira número 33 de Santiago, el acusado ANGELLO LUIS BRAGAZZI PADILLA vendió a un funcionario policial que tenía la calidad de agente revelador, 10 semillas de cannabis sativa por un valor de $\$ 15.000$, previo contacto telefónico realizado a su teléfono celular.

El día 15 de mayo de 2006, en el domicilio ubicado en calle Santa Elvira 33, comuna de Santiago, aproximadamente a las 17:39 horas, el acusado Angello Luis Bragazzi Padilla tomó contacto con diversos estudiantes y vendió a Felipe Javier Rodríguez Rocca, un sobre conteniendo diez semillas de cannabis sativa para su cultivo, en la suma de \$15.000.-

Ese mismo día, el acusado mantenía guardados en dicho domicilio, 42 sets de semillas con diferentes sobres, conteniendo en su totalidad 488 semillas de cannabis sativa, la suma de \$20.000 producto de las ventas, además de insumos como fertilizantes de diferente tipo e insumos e implementos para su cultivo, tales como 11 ampolletas, 2 soquetes cerámicos, 10 bolsas transparentes, 36 maceteros de diversos tamaños, 18 sobres vacíos de semillas de cannabis sativa, 102 frascos plásticos, 2 tambores plásticos, 4 enchufes cronometrados y un foco de aluminio, entre otros objetos, todos elementos destinados a su comercialización posterior a terceras personas.

Asimismo, en su domicilio ubicado en calle Santa Julia $N^{\circ} 1150-J$, La Florida, el acusado mantenía guardados la suma de 200 mil pesos en efectivo, dos libretas de aborro del Banco del Estado, un chaleco antibalas de color azul, 6 bolsas plásticas con cierre hermético, numerosos recibos de correos de la empresa TNT, 19 sobres de cartón para encomienda TNT, 19 bolsas plásticas para encomienda TNT, 4 fotografías de plantas del género cannabis, 4 talonarios de cheques del Banco Santander Santiago, 27 guias de encomiendas YNT, además de una sustancia vegetal de color verdoso, con aspecto y color similar a la cannabis sativa.

Estos hechos son calificados por la Fiscalía, como constitutivos de TRÁFICO ILÍCITO DE DROGAS, de conformidad con el artículo $3^{\circ}$ en relación con el artículo $1^{\circ}$ inciso $2^{\circ}$ de la Ley 20.000. El imputado a través de los siguientes medios: uso de una página web, utilización de un teléfono móvil, y mediante difusión periodística de su actividad, vendió a un tercero y traficó a título oneroso con la materia prima que sirve para obtener la especie vegetal cannabis sativa, esto es, las semillas de dicha especie vegetal. Artículo 3 inciso $1^{\circ}$ parte final de la Ley 20.000, en relación con el artículo $2^{\circ}$ del DS. 565 de 26.01.1996.

El imputado a través de los siguientes medios: uso de una página web, un teléfono móvil, y mediante difusión periodística de su actividad, vendió a un tercero, y en todo 
caso, indujo, promovió y facilitó el uso o consumo de sumidades floridas de cannabis, al entregar los elementos e instrumentos necesarios para el cultivo, producción y posterior consumo de cannabis, esto es, las semillas de dicha especie vegetal. Art. 3 inciso $1^{\circ}$ parte final de la Ley 20.000".

El Fiscal solicita se le aplique la pena de tres años y un día de presidio menor en su grado máximo, multa de cuarenta unidades tributarias mensuales, más las penas accesorias de inhabilitación absoluta perpetua para cargos y oficios públicos y derechos políticos e inhabilitación absoluta para profesiones titulares mientras dure la condena, el comiso de los efectos e instrumentos con que se ejecutó el delito, entre ellos semillas, insumos para su cultivo, teléfonos celulares y dinero además del pago de las costas de la causa.

\section{DÉCIMO: Valoración de los medios de prueba que fundamentan los hechos} que se han tenido por acreditados. Las conclusiones fácticas referidas en el motivo anterior encuentran sustento en los testimonios y pericias y pruebas recibidas por estos sentenciadores en audiencia de juicio, testimonios que percibidos directamente por el Tribunal -bajo el prisma de la inmediación- han hilado razonadamente la imprecisión de veracidad de ocurrencia y justificado a nuestro entender la configuración de los hechos establecidos

En efecto, en lo tocante a establecer la venta, oferta vía Internet y distribución de semillas de cannabis se contó con los testimonios de los funcionarios policiales Julio Espinoza Durán, oficial al mando de todo el procedimiento investigativo de los hechos y que relató al Tribunal la forma como el acusado procedía a través de su página Web a ofertar la venta de semillas de marihuana, explicó también las escuchas telefónicas oídas al imputado con sus clientes, escuchas que ilustraron al tribunal, al ser oídas, de los detalles inequívocos de tratarse de transacciones, siempre de semillas de cannabis, con el correspondiente asesoramiento técnico para su cultivo. Particularmente importante resultó la participación de este testigo, actuando como agente revelador, al obtener la venta de una porción de semillas por parte del acusado. Refirió también con detalle los seguimientos y vigilancia en el domicilio del hechor, lo regular de la obtención de las órdenes de interceptación telefónica, entrada y registro a domicilio y posterior detención del encausado. Mediante su testimonio y reconocimiento se logró introducir como elementos probatorios fijaciones fotográficas -las que fue describiendo una por una-, el domicilio allanado del acusado y de las especies allí encontradas, como semillas, contenedores, planta de marihuana, dos tambores plásticos, cuatro meceteros de plástico, cuatro timers, ampolletas, un foco de aluminio, sobres vacíos, una bolsa con tierra, bolsas con elementos para absorber agua, contenedores, sales, boletas que se daban, catálogos de semillas, fertilizantes, etc. Expuso e hizo un análisis de las conversaciones sostenidas por el acusado. También refirió las dificultades que se tuvieron para obtener del Servicio de Salud el informe de la droga decomisada, señalando que en el primer caso tuvo que esperar un turno y en la segunda incautación no les fue recibido por argüir el organismo receptor problemas de financiamiento para la pericia. Tal testimonio le pareció al Tribunal dotado de la suficiente coherencia y verosimilitud en la exposición que le concederá pleno valor probatorio, por no encontrarse además contradicho por prueba en contrario. 
Refrendó el testimonio anterior lo expresado en juicio por la testigo Ingrid Díaz Valdés, funcionaria policial a la que le correspondió la entrada y registro del inmueble domicilio del acusado, el que lo describe en sus aspectos físicos y que en su interior se encontraban distintos materiales para el cultivo de la cannabis, según refiere y que fueron detallados también por el deponente anterior. Indicó que le correspondió hacer la cadena de custodia de la semilla decomisada y coincidió con el testigo Espinoza Durán respecto a la imposibilidad de peritaje por el Servicio de Salud por razones de dinero. Indica también que había otras personas con el acusado al momento de su detención y finalmente que no escuchó las grabaciones telefónicas y que escuchó al encausado opinar que su actividad no era ilícita. Tal testimonio tampoco fue contradicho por prueba en contrario y se le dará también pleno valor probatorio por cuanto coincide en los aspectos esenciales con el referido por Espinoza Durán.

A su vez el testigo Mauricio Luque Flores, funcionario policial declaró sobre la participación que tuvo en el procedimiento, en las vigilancias previas que le correspondió efectuar al domicilio del acusado y la entrada y registro de los domicilios de calle Santa Elvira $N^{\circ} 33$-lugar de trabajo del encausado- y el de calle Santa Julia $N^{\circ} 1150$ -J -domicilio particular del mismo-, y detalló con minuciosidad los objetos que se le exhibieron en juicio y que corresponden al segundo domicilio ya señalado, describiendo plantas de marihuana, dos libretas del BancoEstado, cuatro talonarios de cheques del Banco Santander Santiago del imputado, sobres de la Empresa de Correos de Chile, formularios de la misma entidad, bolsas plásticas con el logo de Correos. Finalmente, describió vía fotografías que también le fueron exhibidas el inmueble de calle Santa Julia, sus dependencias, los documentos hallados, disco duro, disketes, catálogos de marihuana, número de la página Web, etc. Este testimonio impresionó a estos sentenciadores como imparcial y verídico y le dará valor en cuanto a las circunstancias expuestas y las fotografías exhibidas.

Por su parte, los dichos de los funcionarios policiales Fabián Fernández Cataldo y Cristian Bracamonte Villalobo, fueron contestes y coherentes en cuanto dieron cuenta de las escuchas telefónicas efectuadas respecto a las conversaciones telefónicas que mantuvo el acusado con sus clientes. Al serles expuestas su grabación, manifestaron los detalles del monitoreo y fueron explicando paso a paso, una vez que se escuchaban las pistas exhibidas al tribunal, de la forma o manera como se ofertaba la venta de semilla y los detalles de orientación respecto al cultivo de esta última. Señalaron al tribunal la manera como el vendedor realizaba la venta -a través de depósitos en su cuenta de ahorro-, al precio que señalaba y la forma de la entrega de los productos al comprador. Especialmente relevante aparece el testimonio de Bracamonte Villalobo que señala que nunca escuchó al acusado dar instrucciones de cómo consumir la droga. Sus testimonios guardaron armonía en cuanto a lo sustancial ya indicado y les da validez a las escuchas telefónicas oídas en juicio y no controvertidas por la defensa.

A su vez el testimonio de César Urrutia Romo, funcionario policial, sirvió para demostrar al Tribunal, la labor que realizó en cuanto a la investigación de la página web closet.cl de propiedad de Angello Bragazzi, describiendo en base a las fotografías que se le exhibieron secuencias que dicen relación con la información contenida en dicha 
página, como lo son su logo, leyendas de plantas, cultivos hidropónicos, tipos de semillas, su forma de uso, sistema de compra utilizado, imágenes de semillas y plantas de marihuana y fotos de cultivos. Se le exhibieron también fotografías que dieron cuenta de los números de ingresos a dicha página de Internet. Luego, a través de su testimonio el Tribunal se interiorizó del examen de disco duro del computador del acusado, del cual se pudieron establecer conversaciones de este último, imágenes de plantas, archivos y logotipos de sobres de semillas de cannabis. Relató que se encontraron CDS y disketes no especificando su contenido. Demostró finalmente su relato que desde la cuenta de correo del señor Bragazzi, las semillas que se ofrecían, cómo era su cultivo y la concurrencia de las personas que veían su página. Su testimonio resultó claro y fue inobjetado por la defensa.

Finalmente, la declaración de Renzo Chacón Navarrete, postproductor, ilustró al tribunal sobre el momento de la detención del acusado y del hecho de la venta de semillas que efectuaba y el valor de las mismas. Refiere que en Internet hay una amplia gama de páginas para interiorizarse respecto de la marihuana, así como la revista Cáñamo. Se dará a su testimonio plena validez, ya que dio razón acabada de sus dichos.

A su vez, la prueba pericial rendida por el Ministerio Público constituida por los testimonios de los peritos químicos Kruuse Ferrada, Pérez González y Melo Reinoso fueron contundentes y coincidentes en cuanto a concluir que las especies incautadas al acusado y que les tocó periciar correspondían a semillas de cannabis sativa. La metodología empleada en el análisis farmacognocico, consistente en cromatografía gaseosa y espectrometría de masas fue especialmente relevante para arribar a la conclusión de la presencia de Ácido Linoleico -elemento constitutivo de las semillas de cannabis- . Sus conclusiones fueron precedidas de una explicación científica y clara respecto a los procedimientos utilizados y dieron una explicación satisfactoria cuando fueron requeridos por los intervinientes y el Tribunal. Su experiencia en la materia fue corroborada por dar cuenta de haber efectuado con anterioridad exámenes del tipo que se les requirió, por el espacio de tiempo que llevan ejerciendo su labor y los cursos y capacitaciones que han llevado a cabo. Especialmente trascendente resultó la opinión unánime de los tres expertos -avalada también por la bibliografía, según dijeron- en cuanto a estimar que las semillas de cannabis no contienen omega9, tetrahidrocannabinol(THC) que es el principio activo de la marihuana y que representa su elemento psicoactivo. La misma opinión unánime consideró que la presencia de THC en las semillas se corresponden con una contaminación que sufre la corteza de la semilla al entrar en contacto con las sumidades floridas y especialmente con la resina de dichas flores. Dieron cuenta del estado de las semillas, de su dimensión y corroboraron -los peritos Pérez González y Melo Reinoso-a través de los gráficos de imágenes que se les exhibieron -de las operaciones realizadas, a las que se les da pleno valor probatorio. Finalmente, por lo expuesto, el Tribunal dará valor probatorio, por estimarse que los peritos fueron rigurosos, objetivos y demostraron conocimientos de su especialidad, por lo que sus conclusiones corresponden al resultado de sus observaciones y compatibles con los conocimientos científicamente afianzados.

En lo relativo a la prueba documental de la Fiscalía, el Tribunal les dará pleno valor probatorio, por no haber sido objetados y haberse incorporado en forma legal mediante 
su lectura resumida los siguientes documentos: Copia de las autorizaciones judiciales de interceptación de comunicaciones telefónicas, orden de detención en contra de Angello Bragazzi Padilla que se estiman realizadas en conformidad a la ley; nueve fotocopias de boletas de venta emitidas por el acusado Bragazzi Padilla respecto a semillas e insumos; once páginas impresas bajo el formato word, que dan cuenta de cartas enviadas por Angello Bragazzi Padilla tanto al SAG como a la Embajada de Holanda, solicitando la primera autorización para cultivar semillas y la segunda a fin de obtener permiso fitosanitario para la internación de material vegetal; al oficio $\mathrm{N}^{\circ}$ STG/.2006/ 183 de la Embajada de Países Bajos en que se menciona que la Embajada no le autoriza la importación de granos de cannabis; oficio $\mathrm{N}^{\circ} 404$ del Servicio Nacional de Aduanas que informa que el acusado no registra actividades de importación; Oficio $\mathrm{N}^{\circ} 1031$ del Servicio Agrícola y Ganadero y resolución exenta $N^{\circ} 5283$ en que se da autorización a Angello Bragazzi Padilla para importar granos de cannabis sativa para el uso de alimentos de mascotas; Oficio No 929 del Servicio Agrícola y Ganadero que señala que no se ha autorizado al acusado para sembrar, plantar, cultivar o cosechar especies vegetales del género cannabis sativa; Oficio $\mathrm{N}^{\circ} 524.06$ y 29 cartillas computacionales del Servicio de Impuestos Internos sobre la información tributaria del acusado en cuanto a su rubro de cultivo de hortalizas, de hidropónicos y comercialización de semillas en invernaderos y otros servicios del área de Telecomunicaciones; y Oficio $\mathrm{N}^{\circ} 414$ del BancoEstado en la que se informa todo el movimiento de la cuenta de ahorro $\mathrm{n}^{\circ} 31460187241$ cuyo titular es don Angello Bragazzi Padilla, y en el consta un variado movimiento de abonos y saldos en el período del día 2 de marzo al 9 de mayo de 2006; portada y página 2 del periódico Las Últimas Noticias de fecha 31 de marzo de 2006, en que en lo sustancial señala el acusado que "el negocio es bueno y legal" y "Que la ley de drogas es su libro de cabecera”; Oficio n 007/2006 del Departamento de Ciencias de la Comunicación de la facultad de Ciencias Físicas y Matemáticas de la Universidad de Chile, que da cuenta que el nombre de dominio closet cl. pertenece a Angello Bragazzi Padilla. Todos estos documentos sirvieron para ilustrar al Tribunal respecto a cada uno de los rubros de que dieron cuenta.

En cuanto a los otros medios de prueba acompañados por el Ministerio Público y que consistieron en diversas fijaciones fotográficas y copias de los audios de las grabaciones telefónicas escuchados en juicio, serán considerados con pleno valor en cuanto a que dieron fe a lo que se escuchó y se vio reflejado en sus gráficas e imágenes y que sirvieron para validar a su vez a los testimonios de los testigos de la Fiscalía cuyo valor probatorio ya se indicó.

En el mismo sentido lo que declaró el acusado ante el Séptimo Juzgado de Garantía el día 7 de agosto de 2006, en cuanto a que luego de declaración del señor Orpis señaló haber dejado de vender semillas un par de semanas y luego de algunas consultas reanudó su actividad y que no vendía otra semilla que no sea cannabis.

En cuanto a la prueba rendida por la defensa, en especial la testimonial del Honorable Senador Ávila, sus declaraciones sólo serán valoradas en cuanto al hecho de que efectivamente el acusado Bragazzi le consultó sobre la licitud de la actividad que estaba realizando en cuanto a la venta y distribución de semillas de cannabis sativa y su 
preocupación en lo relativo del alcance y vigencia del reglamento que establece las sustancias estupefacientes que se sancionan. Se valorará también su declaración en cuanto dio cuenta y afirmó la existencia de un proyecto de ley promovido por el Honorable Senador Orpis en lo relativo a penalizar como delito y establecer como materia prima las semillas de cannabis sativa. En lo referente al resto de su declaración, ya sea por no recordar las discusiones parlamentarias ocurridas y lo debatido en ciertas sesiones que se le consultó no será valorado por no haber aportado certeza sobre los tópicos consultados.

Respecto a la declaración del acusado Angello Bragazzi Padilla, quien depuso renunciando a su derecho a guardar silencio y como medio de defensa, servirán sus dichos en lo relativo a tener por acreditado la efectiva venta de semillas de cannabis sativa a diferentes compradores y de insumos para su cultivo. Se le dará pleno valor probatorio también mediante su declaración a todos los elementos de publicidad que utilizó, ya sea en publicaciones periodísticas como instrucciones impartidas a través de su página web llamada closet $\mathrm{cl}$. Su testimonio también se analizará conjuntamente con el del testigo señor Ávila y de los funcionarios policiales presentados por el Ministerio Público en lo que dice relación con su de idea de estimar toda su actividad carente de ilicitud.

En lo concerniente a la prueba documental rendida, se dará valor probatorio al acta de Recepción n ${ }^{\circ} 544$ de fecha 4 de mayo del Servicio de Salud Metropolitano Norte respecto de cinco semillas incautadas al acusado por una presunta sustancia de marihuana enviada por el BIPE. Su valor sólo estará restringido al hecho tal sólo de la recepción, ya que no hay antecedentes de su examen o pericia por dicho organismo de Salud. Por su parte, el Informe del Fiscal del Tribunal Supremo Español sobre la venta de semillas de cannabis será valorado como ilustrativo para el Tribunal en cuanto hace mención al artículo 13 del Convenio de las Naciones Unidas sobre la materia y de los cuadros I y II de su anexo en cuanto concluyen que no figura la semilla de la planta de cannabis como precursores y erradicada además como estupefacientes por carecer de principios activos. Dicha lectura del documento no fue objetado por el Ministerio Público. El Informe de la Junta Internacional de la Fiscalía de Estupefacientes (JIFE), ilustró al Tribunal en cuanto a que constituye materia prima respecto del opio y la hoja de cocaína y cocaína, concluyendo que se derivan para tales efectos de la planta, se observa al respecto también que no se hizo mención a la marihuana.

Pasando a los otros medios de prueba rendidos por la defensa, se dará pleno valor a la presentación de las 488 semillas de cannabis, las que fueron incorporadas mediante su exhibición y reconocimiento de los intervinientes.

El informe de la Comisión de Constitución, Legislación y Justicia sobre el Proyecto de Ley que despenaliza la siembra, plantación y cultivo de especies vegetales productoras de estupefacientes y su boletín $N^{\circ} 3269$ ilustró al Tribunal sobre el hecho de formar parte del informe, la exposición del abogado Pedro Mendoza en esa sede, en cuanto a ratificar que el Reglamento de la ley de drogas excluye las semillas y las hojas no unidas a las sustancias que se sancionan, y que por tanto quedarían excluidas del tipo.

Se valorará también como efectivo el hecho de haberse presentado un Proyecto de Ley por el Honorable Senador Orpis que sanciona el "Tráfico de materias primas para 
producción de drogas y sustancias psicotrópicas y establece presunción que indica”. En el mismo sentido se ponderarán los dichos del Señor Ruiz Pulido en cuanto a señalar en su trabajo, que "las semillas y las hojas no unidas a las sumidades", por expresa disposición normativa y en la medida en que puedan ser perfectamente aisladas e individualizadas en cuanto tales, son excluidas por el Reglamento de la Ley. Ambos documentos fueron acompañados en juicio con exhibición de la Fiscalía y no objetados en su integridad y autenticidad. A su vez el Oficio FN-161, Instructivo $N^{\circ} 17$ sobre la ley 20.000 del Fiscal Nacional a todos los Fiscales Regionales y adjuntos, respecto a las obligaciones que la normativa legal y reglamentaria del Servicio de Salud, son aceptadas y valoradas positivamente porque representan normativa vigente y reflejan las obligaciones de dicho ente en lo que dice relación con sus obligaciones de plazo de entrega y de remisión de informe de la droga que se es sometida a su examen.

En lo relativo a las publicaciones acompañadas, esto página 10 del diario La Tercera de fecha 15 de octubre de 2007 y página 33 del diario La Tercera del 12 de mayo de 2007 serán valoradas tan solo en cuanto representan opiniones de personalidades que se refieren al tema y que de algún modo puedan ilustrar al Tribunal sobre el punto que es sometido a su juicio.

\section{UNDÉCIMO: Prueba desestimada.}

El Tribunal desestimará la siguiente prueba de los intervinientes: Del Ministerio Público, la documental consistente en el informe de Dicom respecto del acusado Angello Bragazzi Padilla, por no ser relevante su resultado a la discusión planteada en juicio. También desechará el Oficio $n^{\circ} 240$ proveniente de la Oficina Nacional de Interpol, ya que su informe dice relación con Aldo Atilio Bragazzi Padilla y Marco Bragazzi Padilla, sujetos no acusados en el juicio y que no se les vinculó de modo alguno con las actividades o conductas del acusado Angello Bragazzi Padilla.

Respecto de la defensa, se desestimará el Oficio $N^{\circ} 537$ del Jefe de la Bipe y dirigido al Servicio de Salud Metropolitano Norte por estimarse que se encuentra prohibida su incorporación por ser diligencia policial de aquellas que veda expresamente el artículo 334 del Código Procesal Penal.

Se desestimará también por no ser atingente al fondo del asunto sometido a juicio y en el acápite otros medios de prueba, las letras b) Prólogo del Libro del autor Eugenio Zaffaroni; e) oficio FN.358 elaborado por el Señor Guillermo Piedrabuena; h) Informe mundial de drogas del 2006 elaborado por la ONU; i) Copia de la audiencia del fecha 16 de mayo de 2006 del Séptimo Juzgado de Garantía de Santiago y l) Anexo 6 titulado "Los Jueces y la ley de Drogas". 


\section{DUODÉCIMO: Valoración jurídica de los hechos.}

Que los hechos acreditados son para la mayoría del Tribunal, como se dijera en el Veredicto, Atípicos, puesto que no constituyen los ilícitos objeto de la acusación. Para así determinarlo se tienen presente las siguientes consideraciones:

$1^{\circ}$ ) La ley 20.000 contempla en su artículo 63 la remisión a un Reglamento, para los efectos de determinar cuáles son las sustancias y especies vegetales a que se refieren los artículos $1^{\circ}, 2^{\circ}, 5^{\circ}$ y $8^{\circ}$ de la ley, y los requisitos, obligaciones y demás exigencias que deberán cumplirse para el otorgamiento de las autorizaciones a que se refiere el artículo $9^{\circ}$ de la misma ley.

$2^{\circ}$ ) Que el reglamento vigente a la fecha de la ocurrencia de los hechos que motivaron la acusación fiscal era el Decreto $\mathrm{N}^{\circ} 565$ del Ministerio de Justicia publicado en el Diario Oficial el día 26 de enero de 1996, que señalaba en su artículo $2^{\circ}$ como aquellas sustancias estupefacientes o psicotrópicas productoras de dependencia física o síquica a la cannabis (cáñamo indicó), sumidades floridas o con frutos de la planta del género cannabis de los cuales no se ha extraído la resina, cualquiera sea el nombre con que se designe, exceptuando de manera expresa las semillas y las hojas no unidas a las sumidades.

$3^{\circ}$ ) Que de la prueba rendida en juicio ha quedado acreditado que el acusado Bragazzi Padilla vendía, distribuía y promocionaba la venta de semillas de cannabis sativa y no otra sustancia estupefaciente, tal como lo aseveran la prueba testimonial pericial y documental rendida.

$4^{\circ}$ ) Que visto lo anterior a la luz de la acusación y para el efecto práctico de su análisis, se dividirán en dos los hechos típicos por los que se acusó y se dirá : en primer lugar, que la venta por el acusado a un funcionario policial que tenía la calidad de agente revelador de 10 semillas de cannabis sativa por un valor de $\$ 15.000$ es un hecho según la mayoría del Tribunal, claramente atípico, entendiendo por atipicidad, la falta de coincidencia de la conducta concreta con el esquema abstracto contenido en el tipo penal.

$5^{\circ}$ ) Que en el mismo sentido y teniendo en consideración la opinión unánime de los tres peritos químicos farmacéuticos que depusieron en el juicio en cuanto a que las semillas de cannabis no contienen en sí mismas el principio activo del Omega 9 Tetrahidrocannabinol o THC, que es el elemento psicoactivo de la marihuana, así como la ausencia en juicio de probanza que indique el examen proveniente del Servicio de Salud -ente autorizado por la ley para emitir conclusiones respecto a la naturaleza, peso, características, contenido y efectos de las semillas incautadas- se llega a concluir por la mayoría de estos sentenciadores que no puede estimarse tampoco como materia prima para la elaboración de sustancias estupefacientes y psicotrópicas.

$\left.6^{\circ}\right)$ En segundo lugar, y en lo relativo a como lo pretende el Ministerio Público en encuadrar los hechos comprobados en juicio, de venta, difusión periodística de su actividad, uso de una página web, de un teléfono móvil, venta de insumos o elementos necesarios para el cultivo en la figura penal de inducir, promover y facilitar el uso o consumo de sustancias prohibidas, su análisis debe hacerse partiendo del objeto material del delito, en este caso, las semillas incautadas, actividad esencial del acusado del cual se derivan todas las demás que le son anexas. 
El tipo penal en cuestión parte de la base que se debe inducir, promover o facilitar el uso o consumo de una droga, pero no de una droga en abstracto, sino que de una droga concreta y determinada y a persona concreta. Así parece entenderse a la luz de lo que dispone el legislador en el artículo 11 de la misma ley 20.000 que sanciona a aquel que facilite bienes raíces o muebles, para la comisión de delitos determinados y con las sustancias que se indican a propósitos de los artículos $1^{\circ}, 2^{\circ}, 3^{\circ}$ y $8^{\circ}$ de la referida ley. La droga concreta en el caso que nos ocupa no es tal, toda vez que está exceptuada del catálogo de prohibiciones ya visto.

A su vez, la ley habla de inducir, promover o facilitar el uso o consumo de droga, como ya se dijo, y de la declaración del testigo presentado por la Fiscalía don Cristian Bracamonte Villalobo, funcionario policial, encargado de las escuchas telefónicas del acusado con sus clientes, dicho deponente manifestó que de las referidas escuchas no se pudo determinar que el acusado entregara información para el consumo de algún tipo de droga.

Toda la actividad complementaria a la venta de semillas estuvo radicada en dar instrucciones, consejos, proporcionar insumos - estos últimos de venta en cualquier tienda comercial, según su naturaleza-, para la destinación del cultivo de dicha semilla, innocua esta última, a ojos del legislador.

El cultivo de la semilla en sí misma no es hecho reprochable a priori por cuanto el usuario puede obtener el permiso administrativo correspondiente y llevar a cabo un cultivo lícito.

A mayor abundamiento, la oferta que realiza el acusado es genérica, no hay cliente concreto y no facilita la droga. Su actividad se limita a una ayuda con su asesoría, pero sin caer en la ayuda al consumo de un tercero. Tal como lo señala el Profesor Matus en su obra Lecciones de Derecho Penal Chileno y citando al Profesor Etcheberry, que "no pueden entenderse como actos de inducción, promoción o facilitamiento las solas “palabras, consejos o proposiciones”, que fue el núcleo más esencial de la conducta desplegada por el acusado.

$7^{\circ}$ ) En consecuencia, por mandato constitucional la ley penal al crear delitos y penas debe referirse directamente a los hechos que constituyen aquellos y a la naturaleza y límites de éstas, y a juicio de la mayoría de estos sentenciadores, la falta de tipicidad de la venta de semillas de cannabis como actividad principal del acusado se irradia a todas las que son su complemento.

$8^{\circ}$ ) El Tribunal no se referirá a los argumentos del Ministerio Público centrados en la conciencia de la antijuridicidad del acusado por cuanto su análisis requiere que se haga a partir de un hecho típico y antijurídico y para los fines de determinar su culpabilidad.

DECIMOTERCERO: Que atendido lo razonado precedentemente y no habiéndose alcanzado la convicción en los Sentenciadores a que alude el artículo 340 del Código Procesal Penal, se procederá a absolver al acusado Bragazzi Padilla de los cargos imputados por el Ministerio Público. 
Por estas consideraciones y lo dispuesto además, en los artículos 1, 3, 9, 11, 63 de la Ley 20.000; Decreto $\mathrm{N}^{\circ} 565$ del Ministerio de Justicia y artículos 1, 45, 46, 48, 295, 296, 297, 340, 341, 342, 343, 344 y 346, del Código Procesal Penal, se declara:

QUE SE ABSUELVE a Angello Luis Bragazzi Padilla, ya individualizado, de la acusación del Ministerio Público y por la que se le formularon cargos como autor de los delitos de Tráfico ilícito de Drogas hecho ocurrido en esta ciudad de Santiago, hechos ocurridos en fechas indeterminadas del año 2006.

Se exime del pago de las costas del procedimiento al Ministerio Público, por estimarse que sostuvo la acción penal con razones suficientes.

Hágase devolución en su oportunidad de los elementos de prueba incorporados al juicio por los intervinientes.

Regístrese, dése cuenta en su oportunidad al Séptimo Juzgado de Garantía de esta ciudad, para los efectos de su cumplimiento. Hecho, archívese

Se previene que el magistrado señor Flores concurre en la decisión absolutoria haciendo presente que luego del proceso de interpretación, al que los jueces estamos obligados, en este caso del artículo $3^{\circ}$ de la ley 20.000, comprendió (...a través de su análisis normativo y político criminal, toda vez que la naturaleza de la ley penal, no es dogma neutral, sino instrumento jurídico-social que pretende objetivos, Mario Garrido Montt, tomo I, pág. 93 ) que las semillas de cannabis sativa se consideran materia prima que sirven para obtener las plantas de la especie mencionada, por consiguiente, quien realice alguna o algunas de las conductas descritas en el inciso segundo del artículo ya mencionado, trafica con tales materias primas y debe ser sancionado con la pena establecida en el artículo $1^{\circ}$ de la ley 20.000 .

No se dice nada nuevo al señalar que la semilla es un embrión que dará lugar a una nueva planta, luego del proceso de germinación, conteniendo las características genéticas de ésta, en este caso de una planta de "marihuana".

Que, el acusado poseía semillas de esa planta, incluso semillas mejoradas genéticamente, lo que se llama un "banco de semillas", que vendía a sus clientes otorgándoles la información necesaria para su cultivo y las características de cada una. Si con ella se iba a obtener plantas de cannabis sativa que al ser cosechadas y luego consumidas por sus clientes tendrían determinados efectos en ellos, por ejemplo "quedar para adentro", "efusivo", según sus propias palabras.

Que, como se dijo, la naturaleza de la ley penal, no es dogma neutral, sino instrumento jurídico-social que pretende objetivos, siendo de interés de todos los estamentos del Estado la erradicación o disminución del tráfico y consumo de drogas.

Así, la conducta del acusado está encuadrada dentro del tipo penal del artículo $3^{\circ}$ de la ley 20.000, por consiguiente su conducta es típica.

De esa manera, este juez desecha la argumentación de la defensa del acusado en cuanto se habría tenido que tipificar tal conducta, y para ello acompañó un proyecto de ley del Honorable Senador Jaime Orpis.

Para ello basta con leerlo para saber de qué se trata la moción del Honorable Senador, ésta corresponde a un proyecto de ley que interpreta el tipo penal que sanciona el tráfico de materias primas para producción de drogas estupefacientes y sustancias sicotrópicas, 
es decir, ya estaba descrita la conducta en abstracto en la ley penal y con el objeto de evitar interpretaciones judiciales propone sancionarla expresamente, configurándose en una interpretación legal o auténtica.

Sin embargo, en este asunto particular, el acusador fiscal no logró acreditar el hecho punible, por no haberse rendido prueba satisfactoria respecto de las materias primas empleadas para la elaboración de sustancias o drogas estupefacientes o psicotrópicas productoras de dependencia física o síquica, sin contar, en consecuencia, con un protocolo de análisis químico e informe de los componentes, efectos y peligrosidad de las sustancias incautadas, lo que sólo puede ser acreditado de la forma ordenada en el artículo 41 de la ley antes citada, no obstante lo establecido en el artículo 297 del Código Procesal Penal, en cuanto a la valoración de la prueba, existiendo, según este juez, una colisión de leyes de igual rango, por lo que optó por preferir aquella que al ser aplicada produce efectos beneficiosos para el acusado.

En efecto, los tribunales apreciarán la prueba con libertad, pero no podrán contradecir los principios de la lógica, las máximas de la experiencia y los conocimientos científicamente afianzados, según lo indicado en el inciso $1^{\circ}$ del artículo 297 del Código Procesal Penal, consagrando de esa manera explícitamente el sistema de libre convicción o sana crítica racional como el sistema de valoración de la prueba.

No obstante ello, la ley 20.000 en el artículo 41, en relación a las sustancias o materias primas empleadas para la elaboración de sustancias o drogas estupefacientes o psicotrópicas productoras de dependencia física o síquica, ordena que sean entregadas al Servicio de Salud que corresponda, y el artículo 43 de la citada ley dispone que tal Servicio, remitirá al Ministerio Público un protocolo de análisis químico e informe de los componentes, efectos y peligrosidad de las sustancias incautadas.

De tal suerte que pareciera que se vuelve a un sistema de prueba legal o tasada.

Que, careciendo del protocolo mencionado y no obstante los informes periciales incorporados mediante la declaración de los propios peritos, quien previene, fue partidario de exigir que se acompañaran los protocolos mencionados con el objeto de identificar el producto, su naturaleza, contenido, composición, componentes tóxicos y sicoactivos, de la materia prima incautada.

Redactada por el Juez titular don Pedro Suárez Nieto y la prevención por su autor.

Ruc N0600200858-9

Rit $\mathrm{N}^{\circ} 11-2008$

Dictado por los Jueces del Cuarto Tribunal de Juicio Oral en lo Penal de Santiago, don Antonio Ulloa Márquez quien presidió, don José Flores Ramírez y don Pedro Suárez Nieto.

\section{COMENTARio}

De sentencia parcialmente reproducida podemos destacar de manera sucinta las siguientes cuestiones jurídico-penales: 
a) El principio de legalidad: ley penal en blanco y el mandato de lex stricta. El primer interrogante que suscita la sentencia comentada radica en la relevancia del Reglamento (DS, $\left.\mathrm{N}^{\circ} 565,1995\right)$ a la hora de determinar el injusto típico del tipo básico tráfico de drogas, denominado también como tráfico en sentido amplio. La argumentación del Ministerio Público es sencilla: la omisión de las semillas de cannabis en los listados recogidos en el citado Reglamento no obsta para que las conductas relacionadas con el tráfico de semillas puedan entenderse como una modalidad de inducción o promoción al consumo de drogas, ya que la conducta realizada por el imputado (traficar con semillas) constituye un acto positivo y directo a la promoción del consumo de drogas. Por tanto, y aceptando que el tipo básico no ha sido estructurado como una ley penal en blanco, el cumplimiento del principio de legalidad se traslada al mandato de lex stricta que, como criterio interpretativo, cobra aquí plena vigencia ante una cláusula indeterminada inserta en un delito de peligro abstracto que, como únicos límites punitivos, se encuentran la determinación judicial de la conducta típica y de la puesta en peligro del bien jurídico protegido. En otras palabras, la indeterminación de la conducta típica y la gravedad de las sanciones impuestas exigen un cumplimiento más estricto del principio de legalidad.

El Ministerio Público concluye que la venta de semillas de cannabis e insumos para su cultivo pone en peligro el bien jurídico protegido, ya que supone una "difusión incontrolable de las sustancias prohibidas". Esta afirmación requiere una previa clasificación de las diversas infracciones que contempla nuestra Legislación penal destinadas a proteger la salud pública En el caso del tráfico de drogas nos encontramos ante un bien jurídico disponible, en el sentido de que la víctima posee un mayor dominio en la puesta en peligro de su salud (delitos de riesgos disponibles), en contraposición con otras figuras relacionadas con la salud pública donde la víctima ostenta un menor o nulo dominio de dicho peligro (delitos de riesgos indisponibles). Así, a modo de ejemplo, cuando se realiza un vertido a un río de sustancias que pueden poner en peligro la salud pública, las posibles personas que se pueden ver afectadas no controlan o disponen de este peligro (Art. 291 CP). Por lo tanto, el término de "incontrolable" debe matizarse en estas figuras en la medida de que la "incontrabilidad" depende esencialmente de que el sujeto quiera consumir drogas, de ahí podemos colegir que lo que se exige -como declara el Tribunal- es una inducción, favorecimiento directo a que personas indeterminadas consuman drogas, situación que no concurre en este caso, ya que a lo sumo lo que se promueve directamente es a la compra de semillas e insumos para el cultivo de marihuana. En fin, la función de garantía del denostado principio de legalidad exige una interpretación más stricta a la hora de subsumir los hechos en una figura claramente indeterminada ${ }^{2}$ y con unas penas especialmente severas. ${ }^{3}$

\footnotetext{
${ }^{2}$ Además, desde una interpretación sistemática el tratamiento penal del tráfico de drogas -conforme con la tradición jurídico penal estadounidense que tiende a detallar con una minuciosidad reiterativa todas las posibles conductas del denominado ciclo de la droga-constituye un argumento adicional para limitar el ámbito de aplicación del tipo básico de tráfico de drogas.

${ }^{3}$ Respecto a la relación de proporcionalidad entre el mandato de lex stricta y la gravedad de la pena, por todos en la doctrina alemana: Schmidt, Rolf, Strafrecht Allgemeiner Teil. Grundlagen der Strafbarkeit Aufbau
} 
b) La puesta en peligro del bien jurídico protegido. En el supuesto de que se considere la venta de semillas como una modalidad específica de favorecimiento al consumo de drogas o en el futuro se tipificara expresamente a través de nueva reforma de la Ley 20.000 -que a la vista de la evolución legislativa sobre drogas y de los proyectos de ley sobre esta materia que se encuentran en la actualidad en discusión parlamentaria resulta más que probable- deberá comprobarse si la conducta ha puesto en peligro el bien jurídico protegido. A la hora de concretar una difusión incontrolable de las sustancias prohibidas cobra especial relevancia la doctrina jurisprudencial del Tribunal Supremo español sobre la atipicidad en los casos de consumo y cultivo de drogas entre consumidores habituales que podría ser análogamente aplicable al supuesto de hecho in comento ${ }^{4}$, más cuando lo que se "comparte" no es la droga sino las semillas y el método de cultivo. Ahora bien, de acuerdo con la jurisprudencia española dos requisitos entrarían en conflicto: la acción tiene que tener lugar en un recinto o círculo cerrado y no debe existir contraprestación alguna. ${ }^{5}$

c) La falta de conciencia de la antijuricidad: La resolución judicial aborda la posible "falta de coincidencia de la conducta concreta", donde las argumentaciones no parecen del todo claras y, a mi entender, correctas. Por una parte, el Tribunal califica como un error de tipo invencible la falta de venta de semillas a un agente provocador. Respecto a esta última posición, el Tribunal parece inclinarse por la teoría unitaria o extrema del dolo, al calificar como atípica "la falta de coincidencia de la conducta concreta con el esquema abstracto contenido en el tipo penal”, posición que en la actualidad rechaza la mayoría de la doctrina nacional. ${ }^{6}$ Por otra parte, el Ministerio Público, a pesar de citar a insignes penalistas, afirma que el conocimiento del reglamento por parte del acusado y la constatación de que las semillas no se encuentran en ninguno de sus listados resulta irrelevante a la hora de establecer la conciencia del injusto. Efectivamente, la doctrina no exige como único criterio el conocimiento exhaustivo de la ley y menos de un reglamento para determinar la conciencia del injusto. La conocida cláusula del "conocimiento paralelo a la esfera del profano" cumple esta función conforme con una noción material del principio de legalidad y del fin preventivo general de las penas, pero, no obsta, para que el conocimiento efectivo de la norma sirva de antecedente para determinar la conciencia del injusto, de hecho, debe jugar un papel relevante en su determinación. Incluso, el error de prohibición requiere una mayor diligencia que la establecida en el error de tipo: quien conoce que realiza un tipo penal conoce también que lesiona un interés, y tiene, por tanto, una espacialísima obligación de preguntarse si lo que hace es lícito o

des strafrechtlichen Gutachtens, (4⿳a ed.) Bremen, (2005), p. 12.

${ }^{4}$ Véase, la doctrina y jurisprudencia citada por Muñoz Sánchez/Soto Navarro, "El uso terapéutico del cannabis y la creación de establecimiento para su adquisición y consumo", (en) Revista de Derecho Penal y Criminología, núm. 7 , pp. 59 y ss.

${ }^{5}$ Véase a los argumentos ofrecidos por Muñoz Sánchez/Soto Navarro en el caso de los establecimientos de consumo y adquisición de derivados de cannabis en la legislación española, "El uso terapéutico...", cit pp. 61-62.

${ }^{6}$ Cury, E. Derecho penal. Parte General, Santiago de Chile, 82205), pp. 434-434. 
no. Si dicho sujeto no responde adecuadamente a la función de llamada del tipo a la hora de analizar el carácter lícito o ilícito de su hecho (error vencible) debe hacerse merecedor, en todo caso, de una pena, que puede atenuarse si consideramos aplicable el error de prohibición vencible a nuestra legislación penal. Pero curiosamente, el acusado ante la sospecha de que su conducta estuviera prohibida al consultar el reglamento e, incluso a un parlamentario, como expresamente reconoce el Ministerio Público, cumplió con la mayor obligación de diligencia que exige la aplicación del error de prohibición.

c) La licitud del autocultivo de marihuana como expresión del modelo políticocriminal de reducción de daños. Por último, esta sentencia supone una manifestación latente de uno de los modelos más recientes de intervención pública en materia de consumo y tráfico de drogas. Las medidas o políticas de reducción de daños que, sin cuestionar de manera directa la actual política criminal centrada en la represión penal y sin proponer de manera directa su despenalización, asume implícitamente el fracaso del objetivo de erradicar el tráfico de drogas y centra sus esfuerzos en mitigar los daños derivados de su consumo. ${ }^{7}$ Estas acciones tratan de facilitar o crear las condiciones para un consumo seguro, diminuyéndose así los riesgos de adulteración de las sustancias psicotrópicas o del contagio de enfermedades. La creación de establecimientos para consumir y adquirir sustancias psicotrópicas, como por ejemplo, los conocidos coffee shops holandeses, constituye una de las principales manifestaciones de este modelo político criminal. Este modelo también se ha reflejado en la jurisprudencia española como una fundamentación adicional para declarar la atipicidad del "consumo compartido" y la de ciertos casos de donación a drogodependientes. Esta línea jurisprudencial, como manifiestan Muñoz Sánchez/Soto Navarro, se han impuesto en la actualidad en la jurisprudencia española que no permitía "ningún resquicio de impunidad". ${ }^{8}$ Incluso, desde la perspectiva de la teoría de la imputación objetiva podría entenderse como un supuesto de exclusión de imputación por disminución del riesgo.

Esta política de reducción de daños resulta aplicable a la realidad del consumo de los derivados del cannabis en Chile, ya que los riesgos a la salud pública derivados que produce la adulteración de la denominada "marihuana paraguaya" supera con creces a los derivados del principio activo y añade otros más mediatos, como a la seguridad personal y pública derivados de la propia criminalización. Quizá, en un futuro no muy lejano las Instituciones chilenas y, en especial el Ministerio Público, se planteen la viabilidad de este modelo política-criminal. ${ }^{9}$

Como conclusión, existen poderosos argumentos para exonerar al sujeto de responsabilidad penal -incluso a los miembros del Tribunal Oral de lo Penal de Santiago y al autor de este comentario- por promover indirectamente el consumo de drogas.

\footnotetext{
${ }^{7}$ Muñoz Sánchez/Soto Navarro, "El uso terapéutico del cannabis y la creación de establecimiento para su adquisición y consumo”, (en) Revista de Derecho Penal y Criminología, núm. 7, p. 49.

${ }^{8}$ Muñoz Sánchez/Soto Navarro, "El uso terapéutico del cannabis...", cit., p. 50.

${ }^{9}$ Nunca está de más recordar que la legalización de facto del consumo y tráfico de drogas en Holanda tantas veces mencionada tiene su origen en la decisión del Ministerio Fiscal de no emprender la persecución penal por el consumo y tráfico de drogas en determinados lugares públicos.
} 